\title{
Need for the Refinement of Licensing Procedure for Pharmacists in India
}

Ramalingam Peraman ${ }^{1}$ and Hari Hara Theja Dugga²

'Raghavendra Institute of Pharmaceutical Education and Research (RIPER), Anantapur, INDIA.

2Drugs control administration, Govt of Andhra Pradesh, INDIA.

E-mail: drramalingamp@gmail.com

DOI: $10.5530 /$ jyp.2016.4.1

As per the Pharmacy practice regulation of Pharmacy council of India, 2015 there are numerous numbers of pharmacist roles have been described in the official gazette of Govt. of India. The participation of a registered pharmacist in health care system is summarized in Table 1.

\section{Table 1: The role of Registered Pharmacist in health care system}

\begin{tabular}{|c|c|}
\hline Patients focused & Drug focused \\
\hline $\begin{array}{c}\text { - patient delicacy, } \\
\text { - patient secrecy, } \\
\text { - patient compliance, } \\
\text { - therapeutic efficacy, } \\
\text { - patient counseling, } \\
\text { - community health services, } \\
\text { - secret remedies, } \\
\text { - prognosis, } \\
\text { - Education program } \\
\text { Patient medication review }\end{array}$ & $\begin{array}{c}\text { - Pharmaceutical care, } \\
\text { - dispensing, } \\
\text { - compounding, } \\
\text { rational use of drugs, } \\
\text { - Trer utilization or under utilization, } \\
\text { - Drug-disease interactions, } \\
\text { - Drug-drug interactions, } \\
\text { - Incorrect drug dosage } \\
\text { Incorrect duration of drug treatment, } \\
\text { - Drug-allergy interactions, } \\
\text { Correlation of availability of drugs, } \\
\text { - Clinical abuse/misuse. } \\
\text { - Drug information services }\end{array}$ \\
\hline
\end{tabular}

Despite of the above roles and participation, the perception of pharmacist in Indiais very weak and especially the community pharmacists are treated as drug traders, obviously they not better than generalor stationery store keepers. In India, a patient - pharmacist relationship has been overlapped with consumers - traders in practice. Only in the purview of educated people, the retail pharmacist is the one who hold a drug licence to supply the medicines. The rest of the fact, described in above tables is absolute paucity in the view of public.

The cause for this bitter situation and poor recognition of Pharmacist in India, are presumed as follows,

- Unawareness of role of pharmacist among health professionals other than pharmacist, it is not surprise sometime including pharmacist. This was reason, why the union government's sixth pay commission was placed the pharmacist in the lowest pay scale band and structure along with other non technical persons.

- Minimum qualification of "Diploma in pharmacy" for a registered
Pharmacist technically inferior as compared to the qualifications of other health professionals (MBBS, B.Sc., nursing etc.)

- In India, licensing procedure has not been placed as gate way for scrutinizing qualified graduate to practice. Instead, it has been placed as re-certification procedure based on minimum qualification.

- Renewal of licence procedure is not conducive to update the knowledge of recent trends or practice. Renewal licence also a process of recertification.

- Communication gap among health professionals as well as among regulatory/statutory bodies like, MCI, PCI, AICTE, Nursing Council etc.

- Lack of well defined regulatory guidelines / law to implement and monitor pharmacy practice services at Hospital set-up.

- Lack of $100 \%$ ethical practice at regulatory and drug control administration that permits the non-pharmacists to dispense medicine.

The above issue are not newly perceived and exists since quite long, the disappointing fact that these issues not even in the phase of elimination though legislative acts such Pharmacy act, Drug and Cosmetic acts are in force. In the view of authors, the possible ways to uplift the image and recognition of Pharmacist role in health care system are,

1. Uplift the minimum qualification criteria and define exclusive standards for registered pharmacist at various positions such as Community Pharmacist, Hospital Pharmacist, and Clinical Pharmacists etc.

2.Educate the role of Pharmacists among other health professionals and initiate inter-professional skill development for Pharmacist with other statutory bodies like Medical council, nursing council etc.

3. Redefine the licensing / renewal procedure for registration of Pharmacists at par with other developed countries such as,

- Introduction of Pharmacist qualifying examination for different positions at health care system.

- Implementation of credit requirement criteria during renewal process.

- Refinement of cancellation/punishment policies for violation of ethics.

\section{CONFLICT OF INTEREST}

Nil.

Correspondence:

Ramalingam Peraman,

Raghavendra Institute of Pharmaceutical Education and Research (RIPER), Anantapur, INDIA

Email: drramalingamp@gmail.com 